\title{
COPD patients prescribed inhaled corticosteroid in primary care: time for re-assessment based on exacerbation rate and blood eosinophils?
}

\author{
Osman Savran ${ }^{1}$, Nina Godtfredsen ${ }^{1,2}$, Torben Sørensen ${ }^{3}$, Christian Jensen ${ }^{4}$ and Charlotte Suppli Ulrik ${ }^{1,2^{*}}$ (1)
}

\begin{abstract}
Background and objective: Inhaled corticosteroid (ICS) therapy for COPD should be guided by exacerbations and blood-eosinophils according to the GOLD 2020 strategy document. In the present study, we applied these recent recommendations in a large cohort of COPD patients recruited from general practice.

Methods: The participating general practitioners $(n=144)$ recruited patients with a diagnosis of COPD currently prescribed ICS and reported data on exacerbation history and blood-eosinophils. Clinical variables were compared using two-sample t-tests.

Results: The study cohort comprised 1,567 COPD patients (44\% males and mean age 72 years). In the past 12 months, 849 (54\%) of the COPD patients currently prescribed ICS had no exacerbation, whereas $383(24 \%)$ and 328 (21\%) patients, respectively, had a history of one exacerbation and two or more exacerbations. Compared to patients with one or no exacerbation, patients with $\geq 2$ exacerbations $(21 \%)$ per year reported more dyspnea $(p<0.001)$ and had higher degree of airflow obstruction $(p<0.001)$. Among patients with no and at least one exacerbation within the preceding 12 months, $30 \%$ and $26 \%$, respectively, had a blood-eosinophil count $\geq 0.3 \times 10^{9} / \mathrm{L}$. In patients with two or more exacerbations within the last 12 months, $77 \%$ had a blood-eosinophil count of $\geq 0.1 \times 10^{9} / \mathrm{L}$. Furthermore, 166 patients (11\%) had at least one hospital admission due to COPD exacerbation, and a blood-eosinophil count of $\geq 0.1 \times 10^{9} / \mathrm{L}$.
\end{abstract}

Conclusion: This study of a large cohort of COPD patients currently prescribed inhaled corticosteroids suggests the need for re-evaluating the management strategy to increase benefit and reduce adverse effects of ICS treatment in COPD patients managed in primary care.

Keywords: COPD, ICS, General practice, Exacerbations, Eosinophils

\section{Introduction}

The 2020 strategy document by the Global Initiative for Chronic Obstructive Lung Disease (GOLD) recommends maintenance therapy with inhaled corticosteroids (ICS)

\footnotetext{
*Correspondence: csulrik@dadlnet.dk

${ }^{1}$ Respiratory Research Unit Hvidovre, Department of Respiratory Medicine, Hvidovre Hospital, 2650 Hvidovre, Denmark
}

Full list of author information is available at the end of the article together with long-acting bronchodilators for COPD patients with a history of frequent exacerbations despite treatment with long-acting bronchodilators alone [1], as previous studies have shown that the benefit of ICS therapy is greater in patients with high risk of exacerbations [2, 3]. Furthermore, the 2019 report by GOLD states that inhaled maintenance treatment with a combination including ICS improves lung function and health 
status in COPD patients [4]. However, this combination therapy is often prescribed as an initial treatment regardless of COPD severity [4]. Furthermore, ICS treatment has also been associated with a high risk of pneumonia in COPD patients [5, 6]. It is therefore imperative to limit ICS treatment to COPD patients who are likely to derive benefit therefrom.

Recent studies indicate that patients with elevated blood-eosinophil count have higher risk of COPD exacerbations [7, 8]. Furthermore, a possible association between the number of blood-eosinophils in COPD patients and the effect of ICS on the occurrence of COPD exacerbations has recently been reported $[7,9,10]$ with the findings suggesting that COPD patients with the highest blood-eosinophil counts and rate of exacerbation benefit the most from ICS treatment [10].

According to the latest report by GOLD, clinical evaluation of exacerbation risk ( $\geq 2$ exacerbations and/or 1 hospitalization in the previous year) together with bloodeosinophils should be taken into account when prescribing ICS for COPD [1]. According to post hoc analyses of a previous study, treatment regimens containing ICS did not benefit patients with a blood-eosinophil count lower than 100 cells/ $\mu \mathrm{L}$ [11]. However, there was a significant favorable effect of ICS treatment in COPD patients with a blood-eosinophil count of more than 300 cells/ $\mu \mathrm{L}$ [8]. Other studies support this proposal and conclude that COPD patients with frequent exacerbations and higher blood-eosinophil counts have reduced exacerbations on ICS treatment, though firm conclusions are limited due to arbitrary cut-off of blood-eosinophil count [10, 12].

In this population-based cohort of COPD patients followed in primary care, our aim was to apply recent proposals from the GOLD strategy document, which indicates that ICS therapy should be guided by exacerbations and blood-eosinophils.

\section{Materials and methods}

Participants included in this study had COPD, were prescribed ICS (coded as International Classification of Primary Care, 2nd ed. code R95 in electronic patient journals and with the ACT code R03AK and R03BA, indicating ICS treatment), and managed in primary care. The selection process of patients participating in the study is summarized in Fig. 1, also illustrating that for the present analysis only patients with information on exacerbation rate and/or blood-eosinophils have been included. General practitioner's (GPs) $(\mathrm{n}=144)$ crosssectional data were collected in 2017; further details have been published previously [13]. In short, data, if eligible, on demographics, blood-eosinophils, previous COPD exacerbations, characteristics and clinical information were collected from GPs to form a large

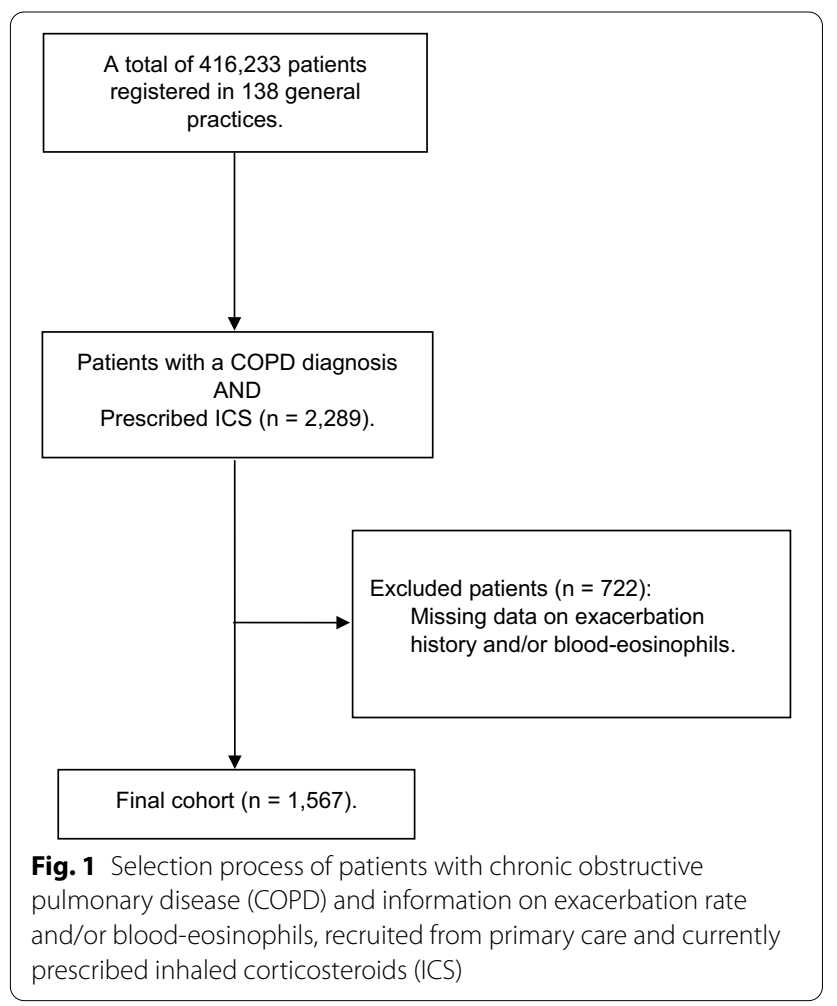

population-based cohort in Denmark. For inclusion, GPs had to provide a maximum of 20 COPD patients who were currently prescribed ICS. Primary care physicians provided anonymized data with only the specified GP having access to patient identity.

\section{Definitions}

Medical Research Council (MRC) scale was used to assess symptom severity. Blood eosinophil levels were classified as high when $\geq 0.3 \times 10^{9} / \mathrm{L}$ and low when $<$ $0.1 \times 10^{9} / \mathrm{L}$ [14]. COPD exacerbations were classified as moderate if the patient had been treated with oral corticosteroid and/or antibiotics out of hospital, with data obtained from the GPs medical records.

\section{Data analysis}

Data were reported as mean values \pm one standard deviation (SD). The baseline characteristics of included patients were calculated, and clinical variables were compared between subgroups of patients using independent $\mathrm{t}$-tests for continuous variables (all included variables fulfilled criteria for normal distribution). A p-value $<0.05$ was considered statistically significant. Data were analyzed using the statistical program IBM SPSS version 25 (IBM Corporation, Armonk, NY, USA), and data were 
Table 1 Baseline characteristics of patients with chronic obstructive pulmonary disease (COPD) currently prescribed inhaled corticosteroids (ICS) identified in general practice with complete data on exacerbations and/or blood-eosinophils $(n=1567)$

\begin{tabular}{|c|c|c|}
\hline & $\begin{array}{l}\text { COPD patients }(n= \\
1567)\end{array}$ & Mean (SD) \\
\hline \multicolumn{3}{|l|}{ Sex } \\
\hline Females & $882(56.3 \%)$ & \\
\hline Males & $685(43.7 \%)$ & \\
\hline Age (years) & $1567(100 \%)$ & 71.9 (SD 10.8) \\
\hline Pack-years ${ }^{\mathrm{a}}$ & 639 & 33.2 (SD 21.5) \\
\hline BMI $\left(\mathrm{kg} / \mathrm{m}^{2}\right)$ & 1122 & 26.9 (SD 6.2) \\
\hline \multicolumn{3}{|l|}{ Symptom score } \\
\hline \multicolumn{3}{|l|}{ MRC-score } \\
\hline$\leq 2$ & $368(23.5 \%)$ & \\
\hline$\geq 3$ & $434(27.7 \%)$ & \\
\hline \multicolumn{3}{|l|}{ Spirometry } \\
\hline $\mathrm{FEV}_{1} \%$ pred (\%) & $1249(79.7 \%)$ & 60.0 (SD 23.8) \\
\hline $\mathrm{FEV}_{1}(\mathrm{~L})$ & 1264 (80.7\%) & 1.51 (SD 0.66) \\
\hline $\mathrm{FEV}_{1} / \mathrm{FVC}$ & 1329 (84.8\%) & 0.58 (SD 0.15) \\
\hline
\end{tabular}

COPD chronic obstructive pulmonary disease, $B M I$ body mass index, $M R C$ Medical Research Council, $F E V$ forced expiratory volume in 1. second, FVC forced vital capacity, SD standard deviation

a Pack-years include current smokers and ex-smokers

also entered in Excel (Microsoft, Redmond, WA) spreadsheet for the development of figures.

\section{Results}

Patient characteristics

Of the COPD patients prescribed ICS recruited from general practice $(\mathrm{n}=2,289), 1567(68 \%)$ had complete data on exacerbation history and/or blood-eosinophils from the last 12 months and were, therefore, included in the present analysis; further details are presented in Fig. 1.

In the final cohort of COPD patients, there were more females $(56.3 \%)$ than males, further baseline characteristics of the included patients are given in Table 1.

\section{Exacerbation history}

Of the enrolled patients, $20.9 \%(n=328)$ had a history of two or more exacerbations in the preceding year with $14.9 \%(\mathrm{n}=234)$ of all patients having had at least one hospital admission for COPD within the last 12 months. As shown in Fig. 2, 54\% of patients had not had any exacerbations in the last 12 months. Further details on exacerbation rate is given in Fig. 2.

Compared to patients with $<2$ exacerbations patients with $\geq 2$ exacerbations (21\%) per year had higher MRCscore $(\mathrm{p}<0.001)$ and lower $\mathrm{FEV}_{1} / \mathrm{FVC}(\mathrm{p}<0.001)$. Further details are presented in Tables 2 and 3.

\section{Exacerbations in COPD patients in relation to blood eosinophils}

Among patients with no exacerbations within the preceding 12 months $(\mathrm{n}=849), 30 \%$ had a blood-eosinophil count $\geq 0.3 \times 10^{9} / \mathrm{L}$, compared to $26 \%(\mathrm{n}=101)$

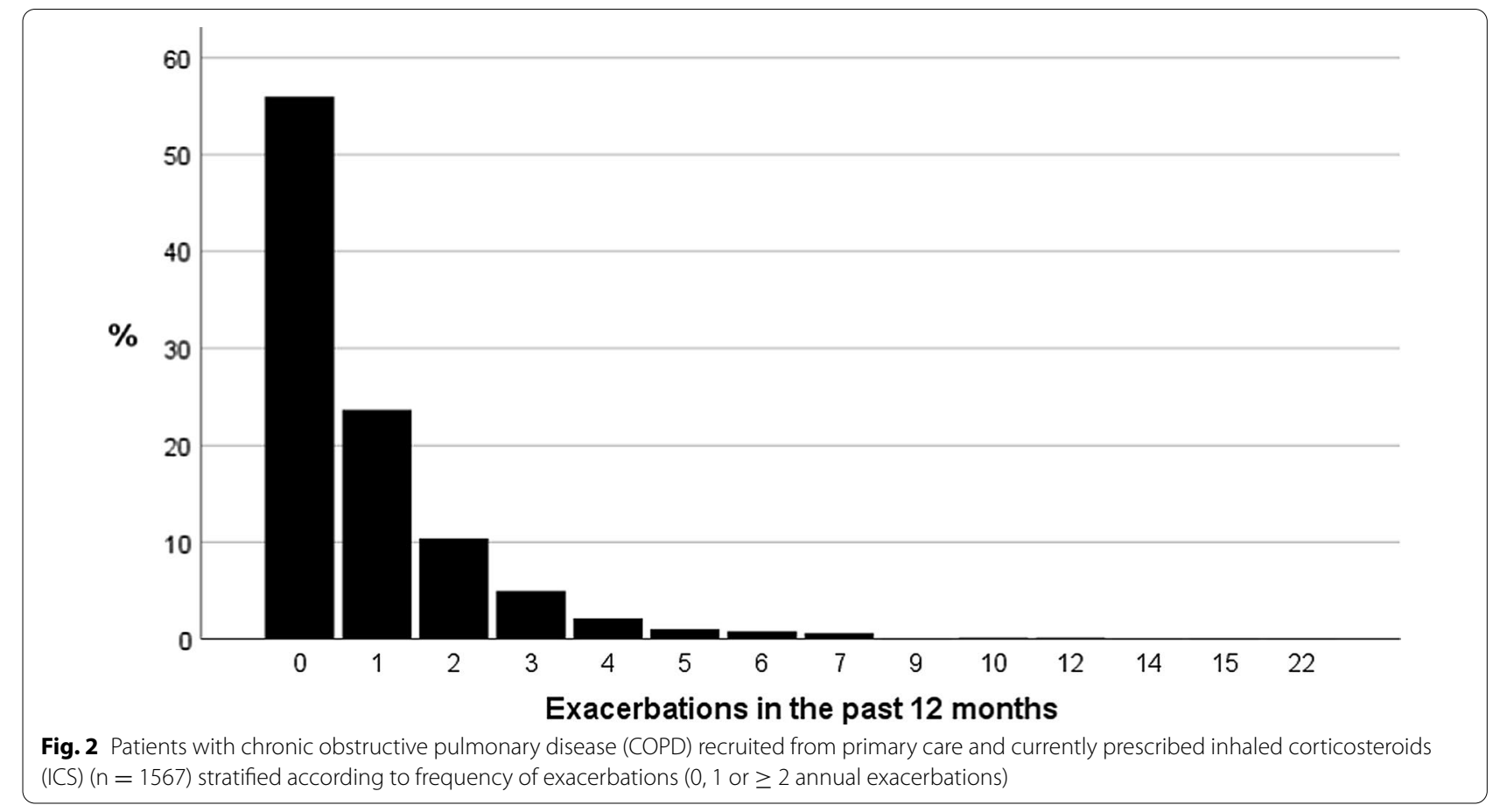


Table 2 Characteristics associated with chronic obstructive pulmonary disease (COPD) patients $(n=1567)$ identified in general practice and currently in inhaled corticosteroid (ICS) treatment stratified by frequency of exacerbations (0, 1 or $\geq 2$ annual exacerbations)

\begin{tabular}{|c|c|c|c|}
\hline & 0 exacerbations per year $(n=849)$ & 1 exacerbation per year $(n=383)$ & $\begin{array}{l}\geq 2 \text { exacerbations } \\
\text { per year }(n=328)\end{array}$ \\
\hline BMI $\left(\mathrm{kg} / \mathrm{m}^{2}\right)$, mean & 27.15 (SD 5.99) & $27.17($ SD 6.12) & 26.28 (SD 6.76) \\
\hline Pack-years, mean & 30.49 (SD 20.89) & 36.04 (SD 22.97) & 36.90 (SD 20.45) \\
\hline $\mathrm{FEV}_{1} / \mathrm{FVC}$, mean & 0.60 (SD 0.14) & 0.57 (SD 0.15) & 0.53 (SD 0.15) \\
\hline $\mathrm{FEV}_{1} \%$ predicted (\%), mean & 64.71 (SD 23.52) & $57.10(S D 22.58)$ & 51.43 (SD 22.99) \\
\hline $\mathrm{FEV}_{1}(\mathrm{~L})$, mean & 1.64 (SD 0.66) & 1.43 (SD 0.62) & 1.27 (SD 0.64) \\
\hline B-eosinophils $\left(10^{9} / \mathrm{L}\right)$, mean & $0.25(\mathrm{SD} 0.21)$ & 0.25 (SD 0.22) & 0.23 (SD 0.19) \\
\hline MRC-score, mean & 2.38 (SD 1.02) & 2.82 (SD 1.11) & 3.20 (SD 1.04) \\
\hline
\end{tabular}

$B M I$ body mass index, FEV 1 forced expiratory volume in 1. second, FVC forced vital capacity, B-eosinophils blood-eosinophils, MRC medical research council, SD standard deviation

Table 3 Prevalence of variables in included cohort

\begin{tabular}{|c|c|c|c|}
\hline & $\begin{array}{l}<2 \text { exacerbation } \\
\text { per year }(n= \\
1230)\end{array}$ & $\begin{array}{l}\geq 2 \text { exacerbations } \\
\text { per year }(n=327)\end{array}$ & P-value \\
\hline BMI $\left(\mathrm{kg} / \mathrm{m}^{2}\right), n$ & $890(27.16)$ & $229(26.28)$ & 0.55 \\
\hline Pack-years, $n$ & $501(32.24)$ & $134(36.90)$ & 0.26 \\
\hline $\mathrm{FEV}_{1} / \mathrm{FVC}, n$ & $1007(0.59)$ & $253(0.53)$ & $<0.001$ \\
\hline $\begin{array}{l}\mathrm{FEV}_{1} \% \text { predicted } \\
(\%), n\end{array}$ & $980(62.37)$ & $265(51.43)$ & $<0.001$ \\
\hline $\mathrm{FEV}_{1}(\mathrm{~L}), n$ & $1052(1.57)$ & $271(1.27)$ & $<0.001$ \\
\hline $\begin{array}{l}\text { B-eosinophils } \\
\left(10^{9} / \mathrm{L}\right), n\end{array}$ & $1232(0.25)$ & $328(0.23)$ & 0.17 \\
\hline MRC-score, $n$ & $604(2.53)$ & $196(3.20)$ & $<0.001$ \\
\hline
\end{tabular}

$B M I$ body mass index, $F E V$, forced expiratory volume in 1. second, FVC forced vital capacity, $B$-eosinophils blood-eosinophils, $M R C$ medical research council

P-values less than 0.05 are considered statistically significant (displayed in italic text) and calculated for the difference between the subgroup $<2$ and $\geq 2$ exacerbations per year

in patients with a history of at least one exacerbation. In patients with two or more exacerbations within the last 12 months, $77 \%$ had a blood-eosinophil count of $\geq 0.1 \times$ $10^{9} / \mathrm{L}$, and, furthermore, 166 patients $(10.6 \%)$ had at least one exacerbation, at least one hospital admission due to COPD exacerbation, and a blood-eosinophil count of $\geq$ $0.1 \times 10^{9} / \mathrm{L}$. Further details on frequency of exacerbations in relation to blood-eosinophils are given in Fig. 3.

\section{Treatment for COPD exacerbations according to blood eosinophils}

In those with a blood-eosinophil count $\leq 0.1 \times 10^{9} / \mathrm{L}$ and a minimum of two moderate exacerbations within the last year $(\mathrm{n}=91), 17$ patients were more likely to be treated with systemic corticosteroids than antibiotics, while 33 patients were prescribed more antibiotics than corticosteroids the preceding 12 months. In this group of

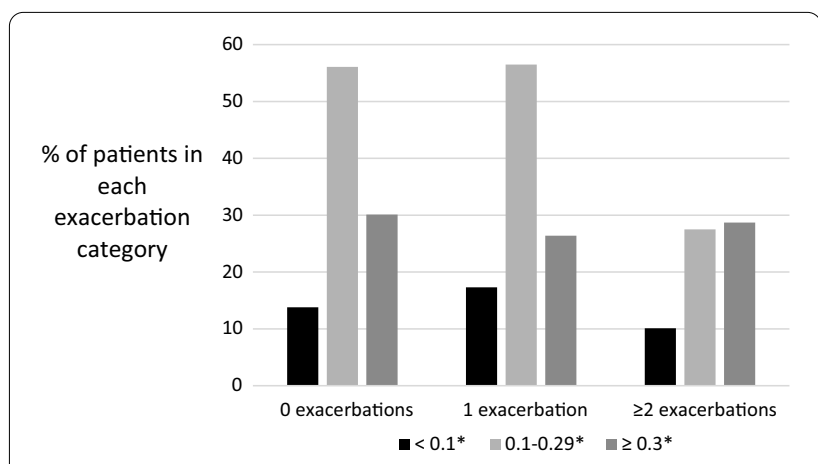

Fig. 3 Patients with chronic obstructive pulmonary disease (COPD) recruited from primary care and currently prescribed inhaled corticosteroids (ICS) ( $n=1567)$ stratified according to annual number of exacerbations $(0,1$ or $\geq 2)$ and blood-eosinophil count

patients, 49 patients (54\%) were treated with long-acting muscarinic antagonists (LAMA).

In those with a blood-eosinophil count $\geq 0.3 \times 10^{9} / \mathrm{L}$ and a minimum of two moderate exacerbations within the last year $(\mathrm{n}=88), 13$ patients had more treatments with corticosteroids than antibiotics, while 44 (50\%) patients were prescribed more antibiotics than corticosteroids within the last year. In this group of patients, 42 patients were treated with LAMA.

\section{Discussion}

The present study of a large cohort of COPD patients managed in primary care and currently prescribed ICS showed that $54 \%$ of the patients had no exacerbation within the last 12 months, whereas $21 \%$ had a history of two or more exacerbations. Among patients with no history of exacerbations, $30 \%$ had a blood-eosinophil count $\geq 0.3 \times 10^{9} / \mathrm{L}$.

Contrary to the strategy document by GOLD, which provides guidelines for physicians on when to consider 
ICS treatment, the Danish Society of Respiratory Medicine provides recommendations on de-escalation of ICS maintenance therapy in COPD patients without exacerbations or hospitalizations for at least one year due to COPD [15]. In short, a physician may consider halve the dose of ICS and await results for 3 months. If FEV ${ }_{1}$ is more than fifty percent complete withdrawal of ICS may happen followed by a follow-up 3 months later for lung function measurement and assessment of clinical condition. These recommendations may also apply to COPD patients, who have been in ICS and LABA treatment for a long period of time without clear indication.

Consideration of ICS add-on maintenance treatment can be made, according to GOLD, based on exacerbations and symptoms. More specifically in those with a blood-eosinophil count of $\geq 0.1 \times 10^{9} / \mathrm{L}$ and a history of two or more moderate exacerbations or a blood-eosinophil count of $\geq 0.3 \times 10^{9} / \mathrm{L}$ [1]. These recommendations facilitate the use of ICS treatment for the prevention of exacerbations in accordance with recent clinical trials presented by a recent post-hoc analysis, which regards blood-eosinophils as a determinant of the benefit of ICS in preventing future COPD exacerbations and presents results indicating a greater benefit of ICS in patients with higher eosinophil count [11]. Almost no effect was reported in those with a blood-eosinophil count less than $0.1 \times 10^{9} / \mathrm{L}$, which naturally has been the threshold where patients are most unlikely to benefit from ICS maintenance treatment [11]. Conversely, patients with a blood-eosinophil count of $\geq 0.3 \times 10^{9} / \mathrm{L}$ have the most benefit from ICS treatment [9]. However, the idea of blood-eosinophils being a biomarker for exacerbation risk is insufficient. Studies have found that bloodeosinophils have less likelihood in determining the future exacerbation risk [16]. Our findings indicate that a substantial proportion of COPD patients prescribed ICS are likely not to benefit from this treatment, as almost onefifth of the included COPD patients had no exacerbations and blood-eosinophils of less than $0.1 \times 10^{9} / \mathrm{L}$ and were hence not candidates for ICS maintenance therapy according to guidelines.

This study also assessed whether exacerbation treatment had a correlation to blood-eosinophil count in COPD patients in primary care. Our results indicated that prescription of ICS in patients with two or more moderate exacerbations was made despite a blood-eosinophil count $<0.1 \times 10^{9} / \mathrm{L}$. Our study found no correlation between blood-eosinophil count and differences in treatment with corticosteroids and/or antibiotics in COPD exacerbation. According to GOLD, ICS treatment can be considered in patients with two or more moderate exacerbations of COPD per year, while blood-eosinophils $<0.1 \times 10^{9} / \mathrm{L}$ is an argument against ICS treatment [14].
Moreover, a treatment strategy including LAMA/LABA is preferred in patients with a blood-eosinophil count $\leq 0.1 \times 10^{9} / \mathrm{L}$, while LABA/ICS has proven more effective in patients with high blood-eosinophil counts $(>0.3$ $\times 10^{9} / \mathrm{L}$ ) [17]. However, we found that the proportion of patients prescribed LAMA was only slightly different between patients with a blood-eosinophil count $\leq 0.1 \times$ $10^{9} / \mathrm{L}$ and $>0.3 \times 10^{9} / \mathrm{L}$, respectively $(\mathrm{n}=49$ vs 42$)$. On the other hand, if patients experience repeated exacerbations despite appropriate long-acting bronchodilator treatment, add-on treatment with ICS may be considered [14].

Some limitations are worth mentioning in this study. First, this analysis did not include information on exacerbations leading to hospital admittance defined as severe exacerbations. Second, among all patient data provided by GPs only 1567 COPD patients were included due to missing data on blood-eosinophils and/or exacerbation history. This might have over- or underestimated the prevalence of exacerbations and altered the results. In addition, a few variables in this study had rather considerable missing information (Fig. 4). One could argue whether variables with much missing information are comparable to each other. In this study missing information in most variables is almost equally distributed across the groups compared, which makes comparison of groups feasible. This is, however, not the case for the variables MRC-score and pack-years, which may have distorted results. Further details are given in Fig. 5.

A significant correlation between patients with higher blood-eosinophil count and increased risk of exacerbations has previously been proposed indicating that patients might have higher blood-eosinophil count with increasing exacerbation frequency. However, this was not the case in our study [8]. Furthermore, COPD patients in ICS treatment followed in primary care were enrolled in 2017 prior to the release of the newest strategy document by GOLD. This analysis might be considered incomprehensive in the investigation of an endpoint such as general practitioner's use of the GOLD report on exacerbations and blood-eosinophils to guide the prescription of ICS. One could argue on the validity of the application of recent recommendations by GOLD on this population-based large cohort of COPD patients currently prescribed ICS. Nevertheless, this analysis gives an initial retrospective assessment on the ICS prescription pattern in general practice.

There is a need for future studies to evaluate whether primary care physicians have changed ICS prescription behavior due to recent GOLD strategy document. The recent studies pointing to a more beneficial treatment regimen guided by exacerbations and blood-eosinophils could alter the risk-benefit ratio by reducing future 


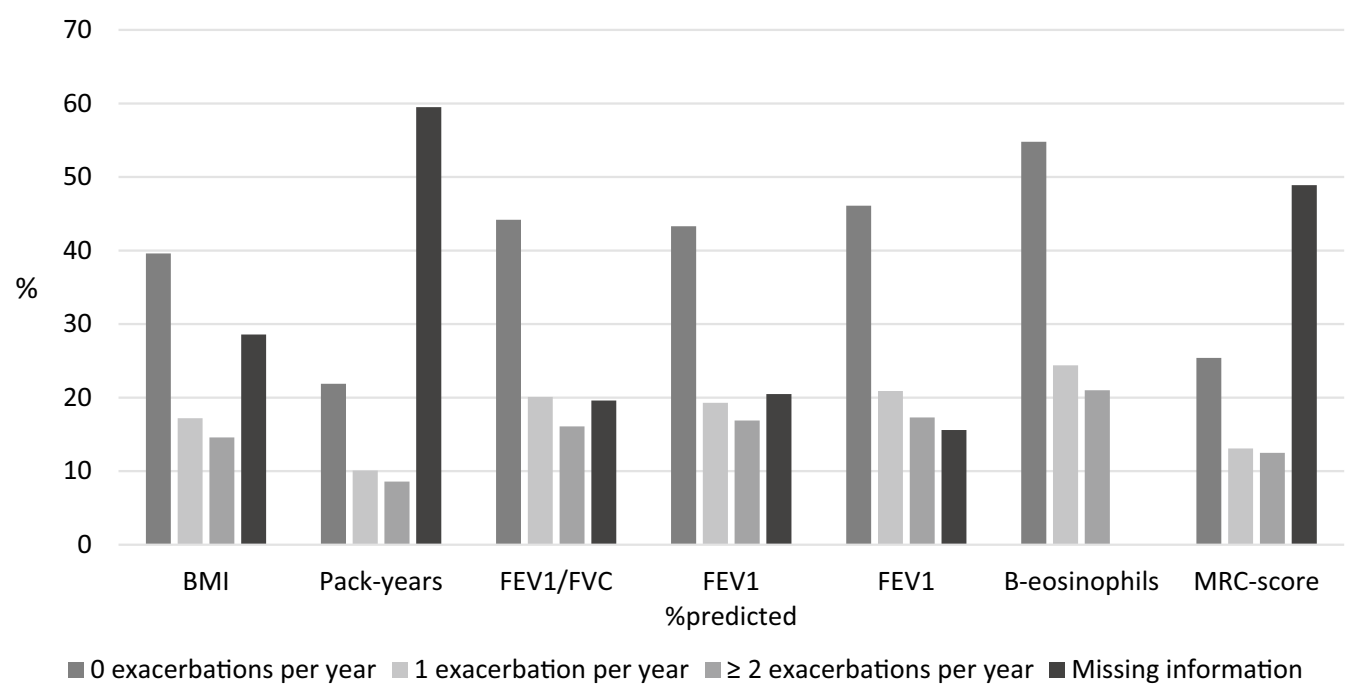

Fig. 4 Percentage of included COPD patients $(n=1567)$ distributed according to variables and stratified by exacerbations per year. BMl body mass index, FEV forced expiratory volume in 1. second, FVC forced vital capacity, B-eosinophils blood-eosinophils, MRC medical research council

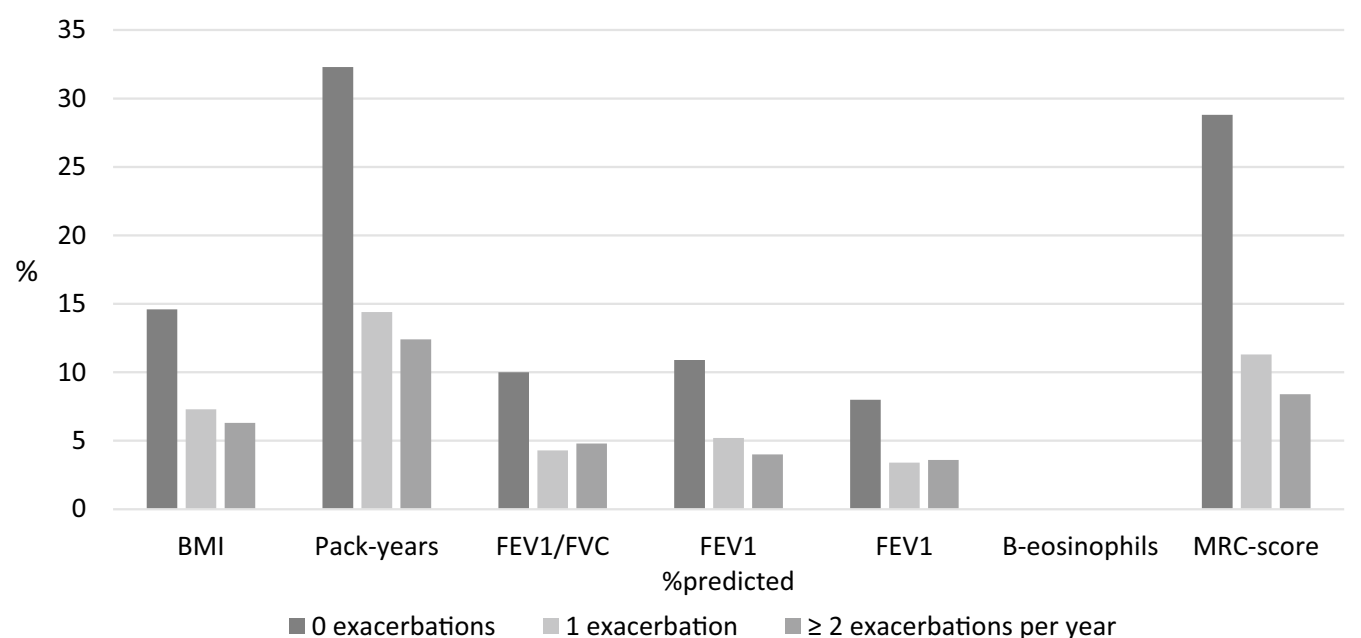

Fig. 5 Distribution of missing information in included COPD patients $(n=1567)$ across variables stratified by exacerbations per year. BMI body mass index, FEV forced expiratory volume in 1. second, FVC forced vital capacity, B-eosinophils blood-eosinophils, MRC medical research council.

incidence of ICS adverse effects and potentially promote the reduction of mortality and COPD-related morbidity in ICS prescribed COPD patients in general practice. Further research is needed to determine to what extent ICS maintenance therapy, in accordance with the recent strategy report by GOLD, benefit COPD patients managed in general practice, and by that, presumably, have less severe disease, as this may pave the way for a more personalized approach to the management of COPD, also in general practice.

\section{Abbreviations}

COPD: Chronic obstructive pulmonary disease; FEV1: Forced expiratory volume in 1. second; FVC: Forced vital capacity; GOLD: Global initiative for chronic obstructive lung disease; GP: General practitioner; ICS: Inhaled corticosteroids; MRC: Medical research council.

\section{Acknowledgements}

Not applicable.

\section{Authors' contributions}

OS drafted the first version of the manuscript. CSU is the guarantor of this study. All authors contributed to drafting and agree to be accountable for all aspects of the work. All authors read and approved the final manuscript. 


\section{Funding}

This study was financially supported by an un-restricted grant from

Boehringer-Ingelheim, Denmark.

\section{Availability of data and materials}

The database will be, upon request, be available from the corresponding author according to current legislation.

\section{Ethics approval and consent to participate}

This study was approved by the Danish Data Protection Agency. This was a non-interventional study, and, consequently, it was not mandatory to obtain approval from the Danish Medicines Agency and the Ethical Committee, but they were, however, provided with full study information.

\section{Consent for publication}

Not applicable.

\section{Competing interests}

OS has received fee for drafting the manuscript (as part of his candidate thesis at the University of Copenhagen) and NSG, TS, CJ and CSU as members of the steering committee of the study from Boehringer-Ingelheim, Denmark. The authors declare that they have no other potential conflicts of interest.

\section{Author details}

${ }^{1}$ Respiratory Research Unit Hvidovre, Department of Respiratory Medicine, Hvidovre Hospital, 2650 Hvidovre, Denmark. ${ }^{2}$ Institute of Clinical Medicine, University of Copenhagen, Copenhagen, Denmark. ${ }^{3}$ Værløse Lægehus, Værløse, Denmark. ${ }^{4}$ Lægehuset Remisen, Præstø, Denmark.

Received: 5 August 2020 Accepted: 7 February 2021

Published online: 12 February 2021

\section{References}

1. Global Strategy for the Diagnosis, Management and Prevention of COPD, Global Initiative for Chronic Obstructive Lung Disease (GOLD) 2019. https ://goldcopd.org/wp-content/uploads/2018/11/GOLD-2019-v1.6-FINAL -08Nov2018-wms.pdf.

2. Wedzicha JA, et al. Indacaterol-Glycopyrronium versus Salmeterol-Fluticasone for COPD. N Engl J Med. 2016;374(23):2222-34.

3. Papi $A$, et al. Extrafine inhaled triple therapy versus dual bronchodilator therapy in chronic obstructive pulmonary disease (TRIBUTE): a double-blind, parallel group, randomised controlled trial. Lancet. 2018;391(10125):1076-84.

4. Rodrigo GJ, et al. LABA/LAMA combinations versus LAMA monotherapy or LABA/ICS in COPD: a systematic review and meta-analysis. Int J Chron Obstruct Pulmon Dis. 2017;12:907-22.
5. DiSantostefano RL, et al. Risk of pneumonia with inhaled corticosteroid versus long-acting bronchodilator regimens in chronic obstructive pulmonary disease: a new-user cohort study. PLoS ONE. 2014;9(5):e97149.

6. Singh S, Amin AV, Loke YK. Long-term use of inhaled corticosteroids and the risk of pneumonia in chronic obstructive pulmonary disease: a metaanalysis. Arch Intern Med. 2009;169(3):219-29.

7. Siddiqui $\mathrm{SH}$, et al. Blood eosinophils: a biomarker of response to extrafine beclomethasone/formoterol in chronic obstructive pulmonary disease. Am J RespirCrit Care Med. 2015;192(4):523-5.

8. Yun $\mathrm{JH}$, et al. Blood eosinophil count thresholds and exacerbations in patients with chronic obstructive pulmonary disease. J Allergy ClinImmunol. 2018;141(6):2037-2047.e10.

9. Pascoe $\mathrm{S}$, et al. Blood eosinophil counts, exacerbations, and response to the addition of inhaled fluticasone furoate to vilanterol in patients with chronic obstructive pulmonary disease: a secondary analysis of data from two parallel randomised controlled trials. Lancet Respir Med. 2015;3(6):435-42.

10. Watz $\mathrm{H}$, et al. Blood eosinophil count and exacerbations in severe chronic obstructive pulmonary disease after withdrawal of inhaled corticosteroids: a post-hoc analysis of the WISDOM trial. Lancet Respir Med. 2016:4(5):390-8.

11. Bafadhel $M$, et al. Predictors of exacerbation risk and response to budesonide in patients with chronic obstructive pulmonary disease: a post-hoc analysis of three randomised trials. Lancet Respir Med. 2018;6(2):117-26.

12. Pavord ID, et al. Blood eosinophils and inhaled corticosteroid/long-acting beta-2 agonist efficacy in COPD. Thorax. 2016;71(2):118-25.

13. Savran O, et al. COPD patients prescribed inhaled corticosteroid in general practice: Based on disease characteristics according to guidelines? ChronRespir Dis. 2019;16:1479973119867949.

14. Global Strategy for the Diagnosis, Management and Prevention of COPD, Global Initiative for Chronic Obstructive Lung Disease (GOLD) 2020. https://goldcopd.org/wp-content/uploads/2019/11/GOLD-2020-REPOR T-ver1.0wms.pdf.

15. Recommendations on de-escalation of ICS treatment on COPD patients. https://www.lungemedicin.dk/fagligt/299-kol-behandling.html.

16. Casanova C, et al. Prevalence of persistent blood eosinophilia: relation to outcomes in patients with COPD. EurRespir J. 2017;50:5.

17. Suissa S, Dell'Aniello S, Ernst P. Comparative effectiveness of LABA-ICS versus LAMA as initial treatment in COPD targeted by blood eosinophils: a population-based cohort study. Lancet Respir Med. 2018;6(11):855-62.

\section{Publisher's Note}

Springer Nature remains neutral with regard to jurisdictional claims in published maps and institutional affiliations.

Ready to submit your research? Choose BMC and benefit from:

- fast, convenient online submission

- thorough peer review by experienced researchers in your field

- rapid publication on acceptance

- support for research data, including large and complex data types

- gold Open Access which fosters wider collaboration and increased citations

- maximum visibility for your research: over 100M website views per year

At BMC, research is always in progress.

Learn more biomedcentral.com/submissions 